\title{
A TOF-SIMS Study of Artificially Photoaged Silk Fabrics
}

\author{
Boyoung Lee | Hyoseon Ryu* | Sohyun Park*,1 \\ Research Laboratory for Archaeology and History of Art, University of Oxford, \\ Oxford, OX1 3UB, United Kingdom \\ *Department of Clothing and Textiles, School of Human Ecology, \\ Seoul National University, Seoul, 04383, Korea \\ **Department of Human Ecology, Korea National Open University, Seoul, 03087, Korea \\ ${ }^{1}$ Corresponding Author: sohyunpark@knou.ac.kr, +82-2-3668-4644
}

\begin{abstract}
Scientific investigation of cultural heritage can provide important information to understand the context of the object. To know the characteristics of the material is also an essential part of objects management and conservation. However, the identification and characterization of organic dyes used in archaeological and historical textiles are often limited by the restrictions in sampling. To cope with the difficulties, applications of high-performance techniques of surface analysis, such as Time of Flight-Secondary Ion Mass Spectra (TOF-SIMS) could be considered as a non or micro-destructive option. This study aims to examine the applicability of TOF-SIMS analysis to the detection of organic dyes from historical textiles. A group of silk fabrics dyed with vegetable dyes were artificially photo-aged to different degrees and analyzed with TOF-SIMS. Molecular and fragment ions from indigo were successfully detected from the aged samples; however, only some fragment ions were observed from gardenia and safflower dyed fabrics. Further studies with actual historical samples with extended examination scope would be necessary to assess the validity of this technique.
\end{abstract}

Key Words: Historical textiles, Artificial ageing, Dye analysis, Non-invasive analysis, TOF-SIMS

\section{Introduction}

Scientific studies of works of art and cultural heritage materials can provide important information, which is essential for the authentication and conservation treatment of the objects. However, identification and characterization of organic dyes used in textiles are difficult for a few reasons. First, the amount of dye compounds adsorbed on the surface of fabrics to form a color is often microscopic, due to the high tinting power of the organic colorants (Chen et al., 2007). In aged samples, the situation is worse because the links between the dye molecules and the fiber surface become weaker and easily fall off. Second, due to the fragile nature of the historical textiles, sampling is often limited under the rules to protect the object. Thus, the focus can be narrowed down to how to effectively examine the samples of limited quantity and quality. To successfully identify the limited traces of dyes from artifacts, the techniques of high-performance surface analysis have been drawing the attention of researchers, especially due to the non-destructive or micro-destructive techniques associated therewith. Time of Flight-Secondary Ion Mass Spectrometry (TOF-SIMS) is a highly capable surface-sensitive analytical method that uses a pulsed ion beam to remove molecules from the outermost surface of the sample (Aoyagi, 2018). It allows a micro-destructive sampling method, and thus can take solid samples as is, or with a simple application of $\mathrm{Ag}^{+}$colloid substrate. Moreover, it can process a variety of data in one short measurement. Thus it is favorable to adopt in analysis of textile artifacts.

In some conventional methods of surface analysis, ATRFTIR for example, it was difficult to distinguish the information from the dyes from the textile background. 
This limited availability was caused by the very low dye content in specimens, and the fact that the fabric and dyes are supposed to have similar functional groups, because they are both made with organic compounds. However, with the TOF-SIMS method, it was possible to detect the presence of the dye compound in considerably aged silk fabrics. Previous studies have successfully detected the major colorant compound from several natural dyes and dyed fabrics using TOF-SIMS technique and found a trace of indigo from a $17^{\text {th }}$ Century textile artifact (Lee et al., 2008; Lee et al., 2013). This implies that TOF-SIMS can be successfully used for the color analysis of some faded textiles. However, there is no criteria for comparison.

Thus in this study, the TOF-SIMS analysis was applied to the range of dyed samples aged to various degrees. The aged fabric samples are made through an artificial ageing of vegetable dyed silks, to avoid the sampling restrictions and waste of historical material. This would also be helpful to avoid the noise disturbance that occurs from organic contaminations in high-sensitivity instrument. Silk fabrics were dyed by traditional Joseon dynasty methods using safflower, gardenia fruit and indigo, with aluminum mordant. The dyed silk fabrics were exposed to an artificial sunlight up to 320 hours. The photo-fading behavior of the surface colors were studied by the color analysis using the colorimeter. The 7 levels of fading was used as the criteria of how further TOF-SIMS analysis can be applied to detect the presence of dyes.

\section{Experimental}

\subsection{Materials}

2.1.1. Test fabric

According to the KS K-ISO 105 Standard Adjacent

Table 1. Characteristics of test fabric

\begin{tabular}{|c|c|c|c|c|c|}
\hline \multirow{2}{*}{ Fiber content } & \multirow{2}{*}{ Weave type } & \multicolumn{2}{|c|}{ Yarn number } & \multirow{2}{*}{$\begin{array}{c}\text { Density } \\
(\text { threads } / 5 \mathrm{~cm})\end{array}$} & \multirow{2}{*}{ Weight $\left(\mathrm{g} / \mathrm{m}^{2}\right)$} \\
\hline & & Warp & Weft & & \\
\hline Silk $100 \%$ & Plain & $21 \mathrm{D}$ & $21 \mathrm{D} / 2$ & $276 \times 192$ & $25 \pm 1$ \\
\hline
\end{tabular}

Table 2. The characteristics of the dyestuffs

\begin{tabular}{|c|c|c|c|}
\hline & Carthamin & Crocin & Indigo \\
\hline $\begin{array}{l}\text { Molecular } \\
\text { formula }\end{array}$ & $\mathrm{C}_{43} \mathrm{H}_{42} \mathrm{O}_{22}$ & $\mathrm{C}_{44} \mathrm{H}_{64} \mathrm{O}_{24}$ & $\mathrm{C}_{16} \mathrm{H}_{10} \mathrm{~N}_{2} \mathrm{O}_{2}$ \\
\hline \multicolumn{4}{|l|}{$\begin{array}{l}\text { Chemical } \\
\text { structure }\end{array}$} \\
\hline $\begin{array}{c}\text { Molecular } \\
\text { weight }(\mathrm{g} / \mathrm{mol})\end{array}$ & 910.787 & 976.972 & 262.268 \\
\hline $\begin{array}{l}\text { Peak mass } \\
\text { for positive } \\
\text { ion }(\mathrm{m} / z)\end{array}$ & $\begin{array}{l}\mathrm{C}_{37} \mathrm{H}_{37} \mathrm{O}_{21}(817) \\
\mathrm{C}_{31} \mathrm{H}_{26} \mathrm{O}_{16}(654) \\
\mathrm{C}_{22} \mathrm{H}_{21} \mathrm{O}_{11}(461) \\
\mathrm{C}_{21} \mathrm{H}_{22} \mathrm{O}_{11}(450) \\
\mathrm{C}_{12} \mathrm{H}_{13} \mathrm{O}_{8}(285) \\
\mathrm{C}_{12} \mathrm{H}_{13} \mathrm{O}_{7}(269)\end{array}$ & $\begin{array}{l}\mathrm{C}_{12} \mathrm{H}_{22} \mathrm{O} 9(310) \\
\mathrm{C}_{11} \mathrm{H}_{20} \mathrm{O} 9(296)\end{array}$ & $\begin{array}{l}\mathrm{C}_{16} \mathrm{H}_{11} \mathrm{~N}_{2} \mathrm{O}_{2} \\
\mathrm{C}_{15} \mathrm{H}_{11} \mathrm{~N}_{2} \mathrm{O}_{2}(235)\end{array}$ \\
\hline
\end{tabular}


Fabrics for Color Fastness Test, the fabric was scoured and washed before dying. The characteristics of test fabric are shown in Table 1.

\subsubsection{Dyes}

For natural dyes, safflower, gardenia fruit and indigo were selected as these are the most common dyes to produce red, yellow and blue from the traditional Korean palette. Safflower and gardenia fruits as dry matter were purchased from a medicinal ingredient supplier. Indigo as natural, fermented and freeze-dried powder was purchased from Tanaka-Nao, Japan. Aluminum Potassium Sulfate $\left[\mathrm{AlK}\left(\mathrm{SO}_{4}\right)_{2}\right]$ as $1^{\text {st }}$ grade as reagent was purchased from Junsei Chemical.

The chemical properties of the dye molecules are shown in Table 2. Safflower (Carthamus tinctorius) contains two major colorants, a water-soluble yellow colorant and an insoluble red colorant known as Safflower Yellow and Safflower Red, respectively. The yellow colorant is a flavonoid compound Safflower yellow (C.I Natural Yellow 5) that can take two forms, Safflomin $\mathrm{A}\left(\mathrm{C}_{27} \mathrm{H}_{32} \mathrm{O}_{16}\right)$ and Safflomin $\mathrm{B}\left(\mathrm{C}_{48} \mathrm{H}_{54} \mathrm{O}_{27}\right)(\mathrm{FAO}, 1997)$. The red colorant is the benzoquinone-derived chemical called Carthamin $\left(\mathrm{C}_{43} \mathrm{H}_{42} \mathrm{O}_{22}\right.$, C.I. Natural Red 26). Gardenia (Gardenia Jasminoides) fruits make a bright shade of yellow that is often called Gardenia Yellow. The major colorant is the carotenoid compound, Crocin (Chen et al., 2008). Indigo (Indigofera tinctoria) is the most common vat dye amongst the natural dyes. Its major colorant is Indigo $\left(\mathrm{C}_{16} \mathrm{H}_{10} \mathrm{~N}_{2} \mathrm{O}_{2}\right.$, C.I. Natural Blue 1). In natural dyes, the colorants present in the form of Indican, a glycoside, and its hydrolysis yields $\beta$-D-glucose and Indoxyl, which forms the blue indigo in reaction with oxygen.

\subsection{Dyeing}

\subsubsection{Safflower dyebath}

The extraction was made according to the protocols in ${ }^{\mathbb{S}}$ Sangbang Jeongrye $\sqrt{\unlhd}$ a $18^{\text {th }}$ Century manual for production of court commodities of Joseon Dynasty. The extraction method is as follows. Safflower (300 g) was left in distilled water to extract the yellow colorants until a clear water runs out. The first extraction of red colorants was made 5 $\mathrm{L}$ of $2 \%$ potassium carbonate solution by immersing the dyestuffs for 3 hours. The second extraction was made in $3 \mathrm{~L}$ of distilled water at $70^{\circ} \mathrm{C}$, with agitation. Schisandra (Schisandra Mongolivaine) vinegar was made from the $100 \mathrm{gs}$ of dried fruits in $1 \mathrm{~L}$ of deionized water, set in a refrigerator for 48 hours. The ready-made vinegar was added to the dyebath to adjust the $\mathrm{pH}$ to 5 (Park et al., 2007).

2.2.2. Gardenia fruits dyebath

$300 \mathrm{~g}$ of dried materials were immersed in $3 \mathrm{~L}$ of deionized water at $40^{\circ} \mathrm{C}$, for 30 minutes. The process was repeated for 3 times to gain total $9 \mathrm{~L}$ of dyebath (Kim and Lee, 2003).

\subsubsection{Indigo bath}

$50 \mathrm{~g}$ of fermented indigo powder was mixed well in $10 \mathrm{~L}$ of deionized water to make a dispersion. Then $50 \mathrm{~g}$ of Soda Ash (Daisho) was added to the vat and heated up to $60^{\circ} \mathrm{C}$. Add $25 \mathrm{~g}$ of Sodium Hydrosulfite (Junsei) and cool down to $40^{\circ} \mathrm{C}$. The temperature was kept at $40^{\circ} \mathrm{C}$ through the dyeing process.

\subsubsection{Dyeing}

Silk fabrics cut to $90 \times 120 \mathrm{~cm}$ were prepared for each dyebath. The fabrics, previously immersed in the deionized water, were treated in the dye baths for 30 minutes at liquor ratio $1: 150$, temperature at $40^{\circ} \mathrm{C}$. For safflower and gardenia fruits dyeing, six cycles of dyeing and mordanting with $2 \% \mathrm{AlK}\left(\mathrm{SO}_{4}\right)_{2}$ solution (on the weight of fabric) was repeated to produce vivid shades (Song and Kim, 2004). For indigo dyeing, two cycles of immersing fabric in the bath for 20 minutes with constant stirring and oxidizing in open air was repeated. The dyed fabrics were rinsed thoroughly with running distilled water until the $\mathrm{pH}$ return to neutral. Indigo dyeing did not require mordanting. Samples were dried in a dark wellventilated room.

\subsection{Artificial ageing}

Samples were cut to $6 \times 12 \mathrm{~cm}$, and clipped to a white 
cardboard panel. In conformance with KS K-ISO 105 B02: 2005, dyed samples were continuously exposed to daylight using a Fade-o-meter. The source of light was Xenon-arc lamp and the temperature of the black panel was set to $63( \pm 1)^{\circ} \mathrm{C}$. The degree of exposure was controlled to 7 steps of $0,10,20,40,80,160$ and $320 \mathrm{hrs}$, based on the Standard Fading Hour method.

\subsection{Analysis of photo-fading behavior}

\subsubsection{Measurement of color change}

In order to analyze photo-fading behavior of the samples, CIE $\mathrm{L}^{*} \mathrm{a} * \mathrm{~b} *$ color space values and $\mathrm{K} / \mathrm{S}$ values were measured by Colorimeter(CM-2600d, Minolta, Japan) in SCI+SCE mode, and the light source is single primary D65, UV $100 \%$. The angle of Observer is $10^{\circ}$, and the perimeter of the measurement was $3 \mathrm{~mm}$. Each samples were folded twice and measured on the top of a matt black panel. The point of measurement was varied four times, and the average value was used. For dyed samples, the value of control group was used as a baseline.

\subsubsection{Detection of dye molecules}

In order to detect the presence of colorant or their fragment ion from aged samples, TOF-SIMS (ION-TOF model 5, ION-TOF GmbH, Germany) was used. Spectrum parameter set is positive polarity, and PI dose is $0.00 \mathrm{E}+$
000 (no additional substrate). Operating spot size and area was $100 \mu \mathrm{m}$ in diameter, and 3 scans per sample from different spots. Measurement time is 90 seconds per sample. The scanning was carried out four times per sample (of each fading stage), and the mean value was automatically recorded. The retrieved SIMS data were processed by MATLAB (R2015a) and Microsoft Excel.

\section{Result and Discussion}

\subsection{Color analysis}

In the color evaluation by naked eyes and colorimeter, all sample groups exhibited a gradual exhaustion of colors as in Figure 1. The intensity of changes was apparent in safflower and gardenia fruit dyed fabrics, however was very small in indigo dyed samples. In CIE $\mathrm{L} * \mathrm{a} \mathrm{b}^{*}$ Color index, $\mathrm{L} *$ value stands for the lightness, and $\mathrm{a}^{*}, \mathrm{~b}^{*}$ stands for the saturation and the hue, respectively (+a/red, -a/green, +b/yellow and -b/blue).

The lightness values were increased in all samples as they ages; on the contrary, saturation and hue values decreased (Figure 2). In safflower and gardenia fruits dyed samples, the color values were converged near to the value of the control, as the degree of ageing accelerated. As indigo is well known for its good fastness, indigo dyed samples exhibited only a small amount of changes
Control

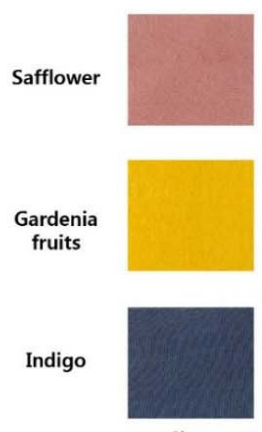

Ohrs
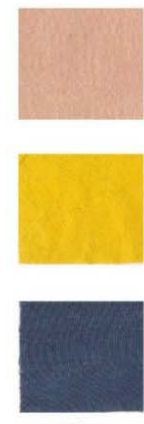

10 hrs
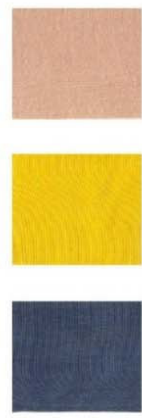

$20 \mathrm{hrs}$

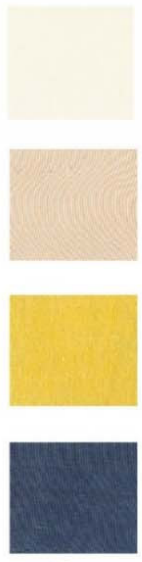

40 hrs

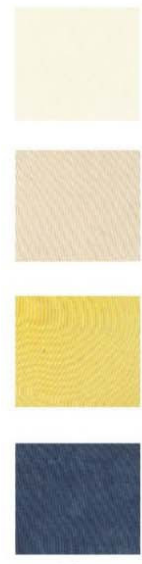

$80 \mathrm{hrs}$

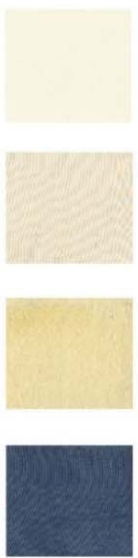

$160 \mathrm{hrs}$

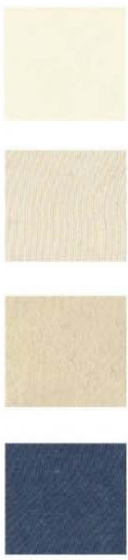

$320 \mathrm{hrs}$

Figure 1. Color fading sequence of the samples. (a) safflower, (b) gardenia, (c) indigo. 
in both saturation and hue.

The K/S value of the samples were calculated from the reflectance (\%) between the wavelength $400 \mathrm{~nm}$ and 700 nm (Figure 3). $\lambda_{\max }$ (absorption maxima) values were found at $530 \mathrm{~nm}$ in safflower dyed samples, $440 \mathrm{~nm}$ in gardenia fruits dyed samples, and $640 \mathrm{~nm}$ in indigo dyed samples, indicating the presence of the major colorants of each dyestuffs. In safflower dyed samples, the $\lambda_{\max }$ at $530 \mathrm{~nm}$ almost disappeared by the $40 \mathrm{hrs}$, and the color value of the sample was almost lost at $160 \mathrm{hrs}$. This implies that the ageing of dye molecules (or the bond between the dye molecules and surface) were accelerated from the $40 \mathrm{hrs}$, and the most of them were degraded by $80 \mathrm{hrs}$; however the loss of major colorants does not immediately affect the loss of shade. A similar tendency was shown in gardenia fruits dyed samples: the value of $\lambda_{\max }$ peak were retarded from ageing $40 \mathrm{hrs}$, and then lost the color value from $320 \mathrm{hrs}$. However, in indigo dyed samples, only a small amount of decrement occurred in the color values throughout the ageing process.

\subsection{Detection of dye compounds by TOF-SIMS Method}

Controls and photo-aged samples were examined with TOF-SIMS to obtain their mass spectrums (Figure 4). The spectrum data were reprocessed using MATLAB.

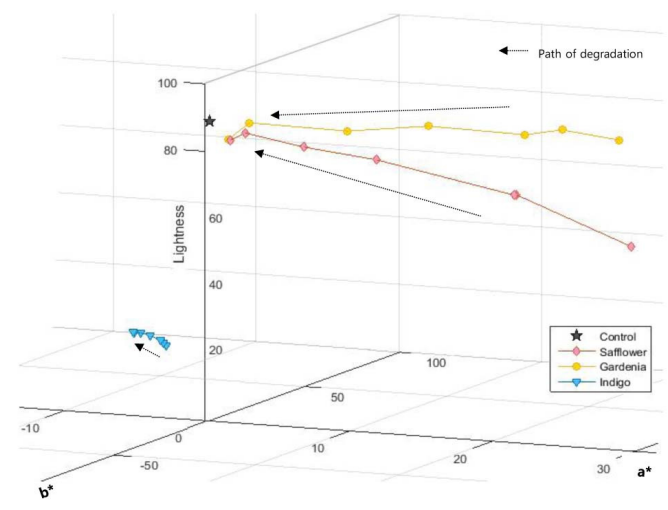

Figure 2. Changes in Lightness $\left(\mathrm{L}^{*}\right), \mathrm{a}^{*}$ and $\mathrm{b}^{*}$ value by time of exposure. [Baseline: control values (undyed specimens) at each ageing step].
First, the peaks lists of each samples were extracted, then the samples of each ageing level were compared to rule out the background information. The intensity value of each characteristic peaks by time of ageing were recorded. In the controls, most of the peaks were observed within $0-200 \mathrm{~m} / \mathrm{z}$, and no significant changes over the level of ageing was appeared.

From the aging samples, some peaks relative to the molecular ions $\left([\mathrm{M}+\mathrm{H}]^{+}\right)$and the characteristic fragmentation of each molecules were observed. A strong peak relevant to the Al mordant was observed at $\mathrm{m} / \mathrm{z} 27$ in all samples. In the safflower and gardenia fruits dyed samples, the molecular ion $\left([\mathrm{M}+\mathrm{H}]^{+}\right)$of carthamin and crocin were not observed from the beginning. This is consistent to the result of Lee et al.(2008), where the mass spectra of the reference molecules of carthamin and crocin were not detected (Lee et al., 2008). Thus, this is independent from the visual loss of color. But it may have been caused from a few reasons: the expected $m / z$ value of carthamin and crocin is near $1000( \pm 100 \mathrm{ppm})$, thus might not have appeared within the range. Carthamin has greater affinity to cellulose fibers than to protein fibers, thus it would be appropriate to be searched in a negative ion area: in which deprotonated molecules of carthamin were detected at [M-H] (-) $m / z 953$ in electrospray negative-ion mode (Sato et al., 2003). Also, in all samples the peaks above $\mathrm{m} / \mathrm{z} 600$ were not well observed, implying that this might have been caused from the poor ionization, as no substrate was applied to minimize the sample damage. Unfortunately, a further examination to clarify the reason could not be done due to the limited time and resources.

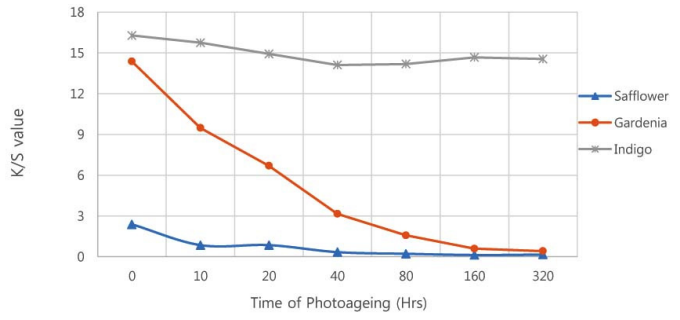

Figure 3. Changes in $\mathrm{K} / \mathrm{S}$ values of the samples (at $\lambda_{\max }$ ) by time. (Baseline: control values at each ageing step). 
However, in indigo dyed samples, $[\mathrm{M}+\mathrm{H}]^{+}$of indigo $\mathrm{m} / \mathrm{z} 263$ was observed throughout the ageing steps, and showed a decreasing behavior in relative intensity except a sudden increment in $40 \mathrm{hrs}$. Two of its fragment ions, $\mathrm{C}_{15} \mathrm{H}_{11} \mathrm{~N}_{2} \mathrm{O} 2(m / z 235)$ and $\mathrm{C}_{16} \mathrm{H}_{11} \mathrm{~N}_{2 \mathrm{O}}(\mathrm{m} / z$ 247) were also observed. Although the degradation of indigo molecules seemed to be accelerated from the 80 hours, the characteristic peaks were well observed throughout all ageing steps. However, some characteristic fragments from the major dye components and the peaks relative to elemental ions from the mordant were also observed. In gardenia fruit dyed samples, weak peaks of fragment ions, $\mathrm{C}_{12} \mathrm{H}_{22} \mathrm{O}_{10}$ (m/z 326), $\mathrm{C}_{11} \mathrm{H}_{20} \mathrm{O}_{9}(m / z ~ 310)$, and $\mathrm{C}_{11} \mathrm{H}_{20} \mathrm{O}_{9}(m / z$ 296)

(a) Carthamin

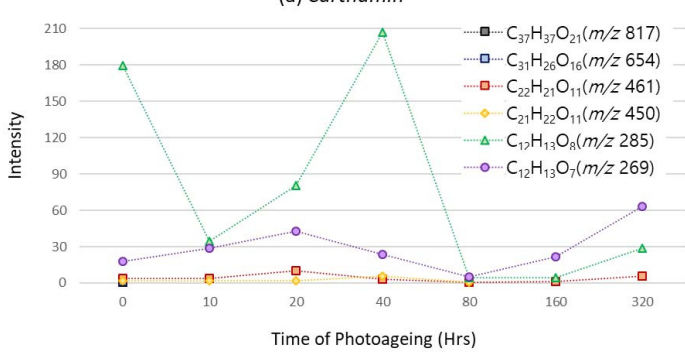

(b) Crocin

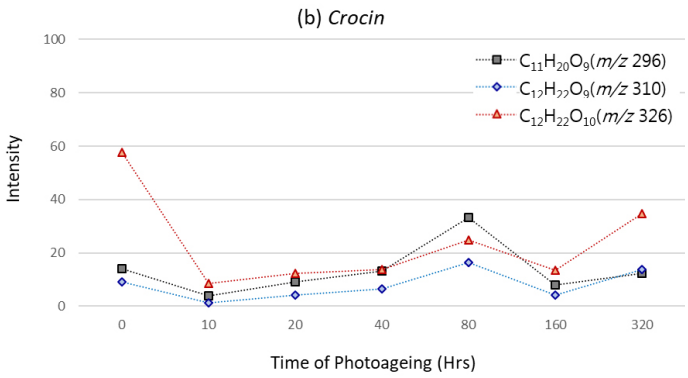

(c) Indigo

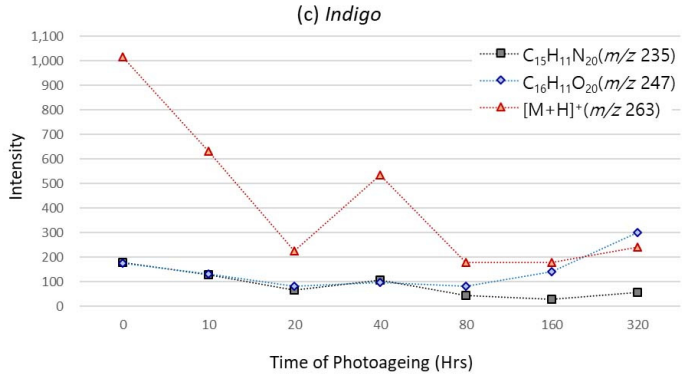

Figure 4. Molecular and fragment ions detected from the photo-aged samples. were observed. In safflower dyed sample, the presence of big fragment ions $\mathrm{C}_{37} \mathrm{H}_{37} \mathrm{O}_{21}\left(\mathrm{~m} / z\right.$ 817) and $\mathrm{C}_{31} \mathrm{H}_{26} \mathrm{O}_{16}(\mathrm{~m} / z$ $654)$ were disappeared from 10 hours; $\mathrm{C}_{21} \mathrm{H}_{22} \mathrm{O}_{11}(\mathrm{~m} / z$ 450) was disappeared after 80 hours; however, a weak peak of $\mathrm{C}_{22} \mathrm{H}_{21} \mathrm{O}_{11}(\mathrm{~m} / \mathrm{z} 461)$ and $\mathrm{C}_{12} \mathrm{H}_{13} \mathrm{O}_{7}(\mathrm{~m} / z$ 269) were observed to 320 hours; $\mathrm{C}_{12} \mathrm{H}_{13} \mathrm{O}_{8}(\mathrm{~m} / z$ 285) showed the strongest intensity among all fragment ions, however largely decreased after 40 hours. Still, the intensities of these fragment ions are much weaker than other peaks observed from the surface of each samples.

In summary, it was possible to detect the trace of dye molecules by TOF-SIMS, from the surface of photo-aged indigo dyed silk fabrics. The molecular ion and fragment ions of indigo were observed without using substrates. However, the molecular ion of crocin and carthamin were not observed from the gardenia fruits and safflower dyed silk fabrics, and only the presence of fragment ions were detected. The result suggests that the TOF-SIMS analysis is applicable to detect natural colorants from the surface of deteriorated silk fabrics, however not suitable to detect big molecules such as crocin and carthamin, which have large MW close to the limit of analytical scope (MW 1,000). The result could be improved by the expansion of measurement scope to the negative ion ranges, and also the use of substrate that accelerates the ionization of the dye molecules. However, it must be noted that this result only suggests a model study of photo-induced degradation that was treated for a limited amount of time; and also, the scans could not be done from the exactly the same spot due to the heat occurs during the measurement.

\section{Conclusions}

TOF-SIMS is an efficient, fast, and non-destructive technique for the characterization of organic dyes found in artificially aged textiles, while avoiding the timeconsuming and destructive extraction procedures. It successful detected the major compounds or their fragment ions of natural dyes from the surface of deteriorated silk fabrics despite the heavy loss of visual colors. TOF-SIMS is a new method for surface analysis that does not require an extra sampling process. 
In this study, it was possible to obtain the surface information from the faded, vegetable dyed silk fabrics without extraction or using substrates, thus minimizing the damage to the samples. However, the method of analysis was not apt to find the trace of big molecules such as crocin and carthamin. Also, it is recommended to scan in both the positive and the negative ion mode, as many of plant-based colorants have negative ion charge.

The advantage of this method was that it was simple to distinguish the information from the dyes and the silk background, and to obtain the quantitative information of the intensity of detected ion in a single operation. Nonetheless, it must be put into consideration that contaminations were minimized in this study to focus on the applicability of TOF-SIMS analysis on faded silk textiles. The applicability to examination of bio-degraded samples are difficult to conclude, because organic contamination could overwrite the original dye information in many excavated (archaeological) samples. Moreover, the high sensitivity of the instrument could result in noise disturbance. The application of TOF-SIMS analysis in identification of archeological dyes is still in the fledgling stage of development and strongly requires further researches with actual archeological samples, which are expected to ensure the validity of the conclusions drawn in this paper.

\section{REFERENCES}

Aoyagi, S., 2018, Time-of-flight secondary ion mass spectrometry. Compendium of Surface and Interface Analysis, Singapore: Springer, 725-731.

Chen, K., Leona, M. and Vo-Dinh, T., 2007, Surface enhanced Raman scattering for identification of organic pigments and dyes in works of art and cultural heritage material. Sensor
Review, 27(2), 109-120.

Chen, Y., Cai, L., Zhao, C., Xu, H.C., Cao, C.Y., Liu, Y., Jia, L., Yin, H.X., Chen, C. and Zhang, H., 2008, Spectroscopic, stability and radical-scavenging properties of a novel pigment from gardenia. Food Chemistry, 109(2), 269-277.

FAO (Food and Agriculture Organization of the United Nations), 1997, Carthamus yellow, in Compendium of Food Additive Specifications. Addendum 5. (FAO Food and Nutrition Paper - 52 Add. 5), Rome: FAO, 198.

Kim, J.P. and Lee, J.J., 2003, Traditional dyes of Korea: Dyes and techniques. Seoul: Seoul National University Press, 87. (in Korean)

Lee, J.H., Kang, M.H., Lee, K.B. and Lee, Y.H., 2013, Characterization of natural dyes and traditional Korean silk fabric by surface analytical techniques. Materials, 6(5), 2007-2025.

Lee, Y., Lee, J., Kim, Y., Choi, S., Ham, S.W. and Kim, K.J., 2008, Investigation of natural dyes and ancient textiles from Korea using TOF-SIMS. Applied Surface Science, 255(4), 1033-1036.

Park, W.J., Kim, K.S., Kim, S.D., Park, J.H. and Koh, J.S., 2007, Korean traditional red dyeing and characterization of its color properties by investigating old documents (I) - Dyeing red shades. The Journal of Textile Science and Engineering, 44 (4), 220-231. (in Korean with English abstract)

Sato, K., Sugimoto, N., Ohta, M., Yamazaki, T., Maitani, T. and Tanamoto, K., 2003, Structure determination of minor red pigment in carthamus red colorant isolated by preparative LC/MS. Food Additives and Contaminants, 20(11), 1015-1022.

Song, H.S. and Kim, B.H., 2004, The beauty of natural dyed traditional colors. Seoul: Sookmyeong University Press, 208-209. (in Korean) 